\title{
Brain Uncoupling Protein 2: Uncoupled Neuronal Mitochondria Predict Thermal Synapses in Homeostatic Centers
}

\author{
Tamas L. Horvath, ${ }^{1,2}$ Craig H. Warden, ${ }^{3}$ Mihaly Hajos, ${ }^{4}$ Assunta Lombardi, ${ }^{5}$ Fernando Goglia, ${ }^{5}$ and \\ Sabrina Diano ${ }^{1}$ \\ 1Department of Obstetrics and Gynecology, and 2Section of Neurobiology, Yale University School of Medicine, New \\ Haven, Connecticut 06520, ${ }^{3}$ Rowe Program in Human Genetics, Department of Pediatrics and Section of Neurobiology, \\ Physiology, and Behavior, School of Medicine, University of California at Davis, Davis, California 95616, ${ }^{4}$ Department of \\ Clinical Pharmacology, University of Oxford, Oxford, United Kingdom OX2 6HE, and ${ }^{5}$ Dipartimento di Fisiologia Generale \\ ed Ambientale, Universita' degli Studi di Napoli "Federico II," Napoli, Italy 80134
}

\begin{abstract}
Distinct brain peptidergic circuits govern peripheral energy homeostasis and related behavior. Here we report that mitochondrial uncoupling protein 2 (UCP2) is expressed discretely in neurons involved in homeostatic regulation. UCP2 protein was associated with the mitochondria of neurons, predominantly in axons and axon terminals. UCP2-producing neurons were found to be the targets of peripheral hormones, including leptin and gonadal steroids, and the presence of UCP2 protein in axonal processes predicted increased local brain mitochondrial uncoupling activity and heat production. In the hypothalamus, perikarya producing corticotropin-releasing factor, vasopressin, oxytocin, and neuropeptide $Y$ also expressed UCP2. Furthermore, axon terminals containing UCP2 innervated diverse hypothalamic neuronal populations. These cells included those
\end{abstract}

producing orexin, melanin-concentrating hormone, and luteinizing hormone-releasing hormone. When c-fos-expressing cells were analyzed in the basal brain after either fasting or cold exposure, it was found that all activated neurons received a robust UCP2 input on their perikarya and proximal dendrites. Thus, our data suggest the novel concept that heat produced by axonal UCP2 modulates neurotransmission in homeostatic centers, thereby coordinating the activity of those brain circuits that regulate daily energy balance and related autonomic and endocrine processes.

Key words: uncoupling proteins; brain; neurons; axon terminals; cranial temperature; proton leak; autonomic and endocrine regulation
The accumulation of body fat is influenced by both central and peripheral processes. CNS signals regulate feeding behavior and energy expenditure of peripheral tissues, whereas brain mechanisms that govern metabolic, autonomic, and endocrine systems are, in turn, influenced by peripheral signals, including leptin, insulin, glucose, glucocorticoids, gonadal steroids, and thyroid hormones (Campfield et al., 1995; Halaas et al., 1995; Pelleymounter et al., 1995; Kalra, 1997; Elmquist et al., 1999; Friedman and Halaas, 1998; Kalra et al., 1999). The complex afferent and efferent pathways involved in the central regulation of metabolism are not well defined. Nevertheless, synaptic interactions between distinct neuronal populations in hypothalamic areas, which are sensitive to peripheral signals, are thought to determine behavioral and humoral responses to changing metabolic states (Kalra and Horvath, 1998; Kalra et al., 1999).

In the attempt to elucidate ways to enhance energy expenditure to diminish fat stores, increasing attention is being paid to energy-dissipating processes and their regulatory components

\footnotetext{
Received July 27, 1999; revised Sept. 13, 1999; accepted Sept. 21, 1999.

This work was supported by National Science Foundation Grant IBN-9728581, National Institutes of Health Grants DK-52581 and DK-35747, the University of California at Davis Health System Research Fund, and Grant LR 3112994 noBO41 from Regione Campania. We are indebted to Drs. Pasko Rakic, Anthony van den Pol, Herold Behrman, and Ferenc Livak for their helpful comments and suggestions. This article is dedicated to the memory of Ilona Csapo (1906-1999), whose life has been an inspiration to all who knew her.

Correspondence should be addressed to Tamas L. Horvath, Department of Obstetrics and Gynecology, Yale Medical School, 333 Cedar Street, New Haven, CT 06520. E-mail: tamas.horvath@yale.edu.

Copyright (C) 1999 Society for Neuroscience 0270-6474/99/1910417-11\$05.00/0
}

(Boss et al., 1998; Gura, 1998). In most eukaryotic cells, energy dissipation occurs, in part, by uncoupling the metabolic chain from oxidative phosphorylation in the mitochondria, thereby, dissipating energy in the form of heat (Nicholls and Locke, 1984; Laloi et al., 1997; Boss et al., 1998; Samec et al., 1998; Simonyan and Skulachev, 1998). This occurs in the inner membranes of mitochondria, where a hydrogen proton gradient exists between the intermembrane space and intramitochondrial space because of the activity of cytochrome oxidases. In the process of storing energy, this proton gradient propels a proton pump located in the inner mitochondrial membrane that moves the proton into the lumen of the mitochondria and uses the positive energy to produce ATP from ADP and P (ATP synthase). However, partial collapse of the proton gradient (proton leak) across the mitochondrial inner membrane induced either by chemicals or proteins partially uncouples the proton gradient from ATP synthesis, resulting in the dissipation of energy in the form of heat. The recent discovery of broadly distributed and regulated mitochondrial uncoupling proteins (UCPs) has provided candidate energy expenditure genes: UCP1, UCP2, and UCP3 (Bouillaud et al., 1985; Klaus et al., 1991; Boss et al., 1997; Fleury et al., 1997; Gong et al., 1997; Liu et al., 1998). Although all these UCPs can promote partial uncoupling of the mitochondrial proton gradient from ATP production in yeast, the mechanism for uncoupling and the physiological substrates for UCP2 and UCP3 when expressed in mammals remain unknown. The three UCPs differ greatly in tissue distribution and regulation and may have distinct physiological roles. UCP1 is expressed only in brown adipose tissue. 
UCP3 is expressed solely in skeletal muscle and the heart in humans. In contrast, UCP2 is widely expressed, although mRNA levels may vary up to 100 -fold between tissues. Of these uncoupling proteins, only UCP2 is expressed in the brain (Fleury et al., 1997; Richard et al., 1998).

The present study was undertaken to investigate UCP2 in the brain to determine whether this uncoupling protein is present in neurons and, if so, to reveal which neuronal circuits operate with this heat-producing mitochondrial device.

\section{MATERIALS AND METHODS}

Animals. A total of 40 adult female and male Sprague Dawley rats $(200-250 \mathrm{gm})$ were used in this study. For the mRNA and protein analyses, 15 animals were kept under standard laboratory conditions, with tap water and regular rat chow available ad libitum; lights were maintained on a $12 \mathrm{hr}$ light/dark cycle. Groups of males $(n=5)$ were killed after either $24 \mathrm{hr}$ of fasting or $16 \mathrm{hr}$ of cold exposure $\left(\right.$ at $4^{\circ} \mathrm{C}$ with food and water available ad libitum). All of these rats were killed under ether anesthesia by transaortic perfusion with $50 \mathrm{ml}$ of heparinized saline followed by $250 \mathrm{ml}$ of fixative. The fixative consisted of $4 \%$ paraformaldehyde, $15 \%$ saturated picric acid, and $0.08 \%$ glutaraldehyde in $0.1 \%$ sodium phosphate buffer (PB), $\mathrm{pH}$ 7.4. Brains were dissected, and 3-mmthick coronal blocks were post-fixed for an additional 1-2 hr. Thirty- or $50-\mu \mathrm{m}$-thick sections were cut on a vibratome. Sections were rinsed in $1 \%$ sodium borohydride in PB for $15 \mathrm{~min}$ to eliminate unbound aldehydes. For the mitochondrial uncoupling and cranial temperature measurements, 10 and 5 male rats were used, respectively (see details below).

The use of animals was approved by the respective University Committees on Animal Use at Yale University, University of Oxford, and University of Naples.

$R T$-PCR. A fragment of 404 bp of cDNA of UCP2 was amplified based on the RT-PCR using specific oligonucleotide primers derived from the coding region of the rat UCP2 sequence (5'-GTC GAA TTC TAC AAG ACC ATT GCA CGA-3' and 5'-TGG GAT CCT CAT AGG TGA CAA ACA TTA- $3^{\prime}$ ). As control, a 603 bp cDNA of rat $\beta$-actin was amplified using the following primers: 5' TAC AAC CTC CTT GCA GCT CC 3' and 5' GGA TCT TCA TGA GGT AGT CAG TC 3'. Total RNA was extracted from the hypothalamus by the guanidium thiocyanate-phenolchloroform method using trizol reagent (Life Technologies, Grand Island, NY) and transcribed using First-Strand cDNA synthesis kit (Pharmacia, Piscataway, NJ). The PCR reaction was performed using the following protocol: $3 \mu \mathrm{g}$ of cDNA templates reacted with $500 \mathrm{~nm}$ primers, $1.25 \mathrm{mM} \mathrm{MgCl}_{2}, 80 \mu \mathrm{M} \mathrm{dNTP}$, and $2 \mathrm{U}$ Taq DNA polymerase. Thermal profiles were $94^{\circ} \mathrm{C}$ for $1 \mathrm{~min}, 60^{\circ} \mathrm{C}$ for $1 \mathrm{~min}$, and $72^{\circ} \mathrm{C}$ for $1 \mathrm{~min}$ for 30 cycles with a final $10 \mathrm{~min}$ extension period.

Northern blot analysis. Ten micrograms of total RNA was electrophoresed on $1.2 \%$ agarose/formaldehyde gels, transferred onto Hybond-N nylon membranes (Amersham, Arlington Heights, IL) by capillary blotting with $10 \times \mathrm{SSC}$, and covalently cross-linked to the membranes using a UV cross-linker (Stratagene, La Jolla, CA). Membranes were prehybridized for $3 \mathrm{hr}$ at $42^{\circ} \mathrm{C}$ in a solution containing $50 \%$ formamide, $5 \times$ SSC, $5 \times$ Denhardt's solution, $1 \%$ SDS, and $100 \mu \mathrm{g}$ of denatured salmon sperm DNA. Hybridization was performed overnight at $42^{\circ} \mathrm{C}$ in the hybridization solution containing $2 \times 10^{6} \mathrm{cpm} / \mathrm{ml}$ of ${ }^{32} \mathrm{P}$-labeled UCP2 probe. After hybridization, membranes were washed in $2 \times \mathrm{SSC} / 0.1 \%$ SDS, followed by two washes in $0.2 \times \mathrm{SSC} / 0.1 \%$ SDS at $55^{\circ} \mathrm{C}$. Membranes were then exposed to $\mathrm{x}$-ray film for $48 \mathrm{hr}$ at $-80^{\circ} \mathrm{C}$. For internal control, membranes were stripped in $0.1 \times \mathrm{SSC}$ and $0.5 \%$ SDS at $95^{\circ} \mathrm{C}$ and then reprobed with ${ }^{32} \mathrm{P}$-labeled $\beta$-actin cDNA probe. For the probe preparations, the 404 bp rat UCP2 cDNA and the 603 bp rat $\beta$-actin cDNA fragments were extracted from agarose gel using QIA quick gel extraction kit (Qiagen, Hilden, Germany) and ${ }^{32}$ P-labeled with $\left[\alpha^{-}{ }^{32} \mathrm{P}\right] \mathrm{dCTP}(10 \mathrm{mCi} / \mathrm{ml}$; Amersham $)$ using a random oligonucleotide primer (Amersham).

In situ hybridization. The PCR product was inserted in Bluescript vector and subcloned. Linearized DNA was transcribed using T7 polymerase (antisense cRNA probe) and T3 polymerase (sense cRNA probe; Riboprobe Combination System T3/T7; Promega, Madison, WI). The radiolabeled cRNA probe was purified by passing the transcription reaction solution over a G50 column (Pharmacia Biotech), and fractions were collected and counted by using a scintillation counter. In situ hybridization: the purified cRNA probes were heated at $80^{\circ} \mathrm{C}$ for $2 \mathrm{~min}$ with $500 \mathrm{mg} / \mathrm{ml}$ yeast tRNA and $50 \mathrm{~mm}$ dithiothreitol (DTT) in water before being diluted to an activity of $5.0 \times 10^{7} \mathrm{dpm} / \mathrm{ml}$ with hybridization buffer containing $50 \%$ formamide, $0.25 \mathrm{M}$ sodium chloride, $1 \times$ Denhardt's solution, and $10 \%$ dextran sulfate. The brains $(n=5)$ were perfused and frozen on dry ice. The frozen brains were allowed to equilibrate in a cryostat at $-20^{\circ} \mathrm{C}$. Coronal sections were cut at $16 \mu \mathrm{m}$ and then mounted onto poly-L-lysine-coated slides. Brain sections were collected, beginning rostrally at the optic chiasma and continuing caudally to the median eminence area. Sections with this hybridization solution $(150 \mu \mathrm{l} / \mathrm{slide})$ were incubated overnight at $50^{\circ} \mathrm{C}$. After hybridization, the slides were washed four times $(10 \mathrm{~min}$ each $)$ in $4 \times \mathrm{SSC}$ before RNase digestion $\left(20 \mu \mathrm{g} / \mathrm{ml}\right.$ for $30 \mathrm{~min}$ at $\left.37^{\circ} \mathrm{C}\right)$ and rinsed at room temperature in decreasing concentrations of SSC that contained $1 \mathrm{~mm}$ DTT $(2 \times, 1 \times$, and $0.5 \times ; 10 \mathrm{~min}$ each $)$ to a final stringency of $0.1 \times \mathrm{SSC}$ at $65^{\circ} \mathrm{C}$ for $30 \mathrm{~min}$. After dehydration in increasing alcohols, the sections were exposed to $\beta$-max hyperfilm (Amersham) for $5 \mathrm{~d}$ before being dipped in Kodak (Eastman Kodak, Rochester, NY) NTB-2 liquid emulsion diluted 1:1 with distilled water. The dipped autoradiograms were developed 21 d later with Kodak D-19 developer, fixed, and the sections were counterstained through the emulsion with hematoxylin. Sections were examined under bright-field and dark-field illumination. As control experiment, sections were incubated as described above with hybridization solution containing the sense-strand probe synthesized with T3 polymerase to transcribe the coding strand of the DNA insert.

Western blot analysis. Rats were killed by decapitation under ether anesthesia. The hypothalamus of each animal was removed and homogenized in lysis buffer containing $50 \mathrm{~mm}$ Tris- $\mathrm{HCl}$, pH 7.5, $50 \mathrm{~mm} \mathrm{MgCl}_{2}$, $5 \mathrm{~mm}$ EGTA, $0.25 \%$ Triton X-100, and protease inhibitors (proteinase inhibitor cocktail tablets; Boehringer Mannheim, Indianapolis, IN). Coomassie-stained SDS-polyacrylamide gels were routinely used to evaluate the quality of the extracts. Western blots were performed using $10 \%$ SDS-polyacrylamide gels run on a minigel apparatus; $25 \mu \mathrm{g}$ of protein was loaded per lane. The gels were transferred to polyvinylidene fluoride (PDVF; Millipore, Bedford, MA) membranes by electroblotting overnight $(30 \mathrm{~V})$. The filters were blocked in $6 \%$ nonfat dry milk and $0.1 \%$ Tween 20 for $1 \mathrm{hr}$ at room temperature. Blots were then incubated with rabbit anti-UCP2 (1:2000) diluted in TBS Tween 20 (TTBS; 20 mM Tris, $137 \mathrm{~mm} \mathrm{NaCl}, \mathrm{pH}$ 7.6) for $1 \mathrm{hr}$ at room temperature. Blots were also incubated with rabbit anti-actin $(1: 10,000)$ (Sigma, St. Louis, MO) as controls to evaluate the amount of proteins loaded for each lane. Membranes were washed three times for $10 \mathrm{~min}$ in the same buffer and incubated for $1 \mathrm{hr}$ with horseradish peroxidase-conjugated goat antirabbit IgG (Vector Laboratories, Burlingame, CA) diluted 1:10,000 in TTBS. Subsequently, the blots were washed five times for $10 \mathrm{~min}$ in the same buffer. Immunoreactive proteins were revealed using enhanced chemiluminescence method (ECL; Amersham).

Light and electron microscopic immunocytochemistry. Sections were incubated with the primary antisera [rabbit anti-UCP2 (1:2000)] for 24 $\mathrm{hr}$ at room temperature. After several washes with $\mathrm{PB}$, sections were incubated in the secondary antibody (biotinylated goat anti-rabbit IgG; 1:250 in PB; Vector Laboratories) for $2 \mathrm{hr}$ at room temperature, then rinsed in $\mathrm{PB}$ three times $10 \mathrm{~min}$ each time, and incubated for $2 \mathrm{hr}$ at room temperature with avidin-biotin-peroxidase (ABC; 1:250 in PB; ABC Elite kit, Vector Laboratories). The immunoreaction was visualized with a modified version of the nickel-diaminobenzidine (Ni-DAB) reaction (15 mg of DAB, $0.12 \mathrm{mg}$ of glucose oxidase, $12 \mathrm{mg}$ of ammonium chloride, $600 \mu \mathrm{l}$ of $0.05 \mathrm{M}$ nickel ammonium sulfate, and $600 \mu \mathrm{l}$ of $10 \%$ $\beta$-D-glucose in $30 \mathrm{ml} \mathrm{PB}$ ) for $10-30 \mathrm{~min}$ at room temperature, resulting in a dark blue reaction product. After immunostaining, the sections were thoroughly rinsed in PB and processed for correlated electron microscopy as follows: sections were osmicated (1\% OsO4 in PB) for $30 \mathrm{~min}$, dehydrated through increasing ethanol concentrations (using 1\% uranyl acetate in the $70 \%$ ethanol for $30 \mathrm{~min}$ ), and flat-embedded in araldite between liquid release-coated slides (Electron Microscopy Sciences, Fort Washington, PA). After capsule embedding, blocks were trimmed. Ribbons of serial ultrathin sections were collected on Formvar-coated single slot grids and examined using a Philips CM-10 electron microscope. Beyond the Western blot analysis, to test the validity of the antiserum, several control experiments were performed in which the primary antiserum was either omitted or preadsorbed with the target peptide. Under these conditions, no immunolabeling was apparent.

Multiple labeling immunohistochemistry for UCP2 and different neuropeptides and hormone receptors was performed according to previously published protocols (Horvath, 1997, 1998; Horvath et al., 1997). In short, vibratome sections were double-immunostained for either UCP2 
and leptin receptor $(\mathrm{ObR})$ or $\mathrm{UCP} 2$ and estrogen receptor (ER) using green- and red-fluorescent secondary antisera. Fluorogold labeling of neuronal elements was assessed by ultraviolet light. Antisera or antibodies were either purchased from commercial vendors [sheep antineuropeptide Y (NPY; Auspep Pty Ltd., Perkwille, Australia), mouse anti-corticotropin-releasing factor (CRF; Biogenezis, Poole, UK), mouse anti-tyrosine hydroxylase (Chemicon, Temecula, CA), mouse antivasopressin (VP; ICN Biochemicals, Costa Mesa, CA), mouse antioxytocin (OX; Diasorin, Stillwater, MN), goat anti-ObR (Santa Cruz Biotechnology, Santa Cruz, CA), rabbit anti-MCH (Phoenix Pharmaceuticals, Mountain View, CA), mouse anti-estrogen receptor (Dako, Glostrup, Denmark), and rabbit anti-androgen receptor (Affinity Bioreagents, Golden, $\mathrm{CO}$ )] or were generously provided by other researchers [rabbit anti-orexin (Dr. A. N. van den Pol), mouse anti-luteinizing hormone-releasing hormone (LHRH; Dr. H. Urbanski)].

Under approved institutional animal protocols, rats $(n=5)$ were food-deprived for $24 \mathrm{hr}$ before killing. Control animals received food $\mathrm{ad}$ libitum. Groups of male rats $(n=5)$ were also exposed to $16 \mathrm{hr}$ of cold $\left(4^{\circ} \mathrm{C}\right)$ during which time food and water was available ad libitum. Brains were perfusion-fixed, and sections of the hypothalami and forebrain were immunolabeled for either c-fos alone or UCP2 and c-fos (sheep anti-cfos, 1:2000; Cambridge Research Biochemicals, Wilmington, DE) using the protocol described above. Sections from experimental and control groups were identified by placing marks on them and were processed in the same vials using the same reagents and timetable. The number of c-fos-expressing cells was calculated for each region. After determination of homogeneity within treatment groups using an $F$ test, values were compared between experimental and control groups using Student's $t$ tests.

Brain mitochondria preparation and measurements of oxygen consumption and membrane potential. In male rats $(n=40)$, mitochondria were isolated from the UCP2-containing basal hypothalamus and from the striatum and lateral thalamus (where both UCP2 mRNA and peptide were absent) according to previously published protocols (Lombardi et al., 1998). In short, each area was homogenized in a medium containing $320 \mathrm{~mm}$ sucrose, $10 \mathrm{~mm}$ Tris, and $1 \mathrm{~mm}$ EGTA adjusted to $\mathrm{pH} 7.4$ with $\mathrm{HCl}$. After centrifugation $(700 \times g ; 5 \mathrm{~min})$, the pellet was rehomogenized before being recentrifuged $(700 \times g ; 5 \mathrm{~min})$. The supernatant from the previous centrifugation steps were pooled and spun at $21,000 \times$ $g$ for $10 \mathrm{~min}$. The pellet was resuspended in $15 \%$ Percoll and layered onto a Percoll gradient and spun at $30,500 \times g$ for $5 \mathrm{~min}$. The material at the interface of the lower two Percoll layers was removed, diluted 1:4 with the isolation buffer, and spun at $16,000 \times g$ for $10 \mathrm{~min}$. The pellet was diluted 10 times with isolation medium and spun at $6000 \times g$ for $10 \mathrm{~min}$. The pellet was gently resuspended and stored on ice. Mitochondrial oxygen consumption was determined using a Clark-type oxygen electrode in an incubation medium containing $80 \mathrm{~mm} \mathrm{KCl}, 50 \mathrm{~mm}$ HEPES, $\mathrm{pH}$ 7, $1 \mathrm{~mm}$ EGTA, $5 \mathrm{~mm} \mathrm{~K}_{2} \mathrm{HPO}_{4}, 4 \mu \mathrm{M}$ rotenone, $80 \mathrm{ng} / \mathrm{ml}$ nigericine, and $1 \mu \mathrm{m} / \mathrm{ml}$ oligomycin using a saturating amount of succinate as substrate at $37^{\circ} \mathrm{C}$.

Intracranial temperature measurements. Brain temperature measurements were performed in chloral hydrate $(450 \mathrm{mg} / \mathrm{kg}$, i.p. $)$-anesthetized rats $(n=5)$ using a Digitron thermometer. Animals were placed in a stereotaxic apparatus (Kopf Instruments) and, after craniotomy, a precalibrated thermocouple (diameter, $0.6 \mathrm{~mm}$; resolution, $0.1^{\circ} \mathrm{C}$ ) was lowered into discrete regions of the thalamus and hypothalamus, in the midline, $2.8 \mathrm{~mm}$ posterior to bregma. Temperature readings were taken in the mediodorsal thalamus (ventral coordinate, $5.4 \mathrm{~mm}$ ), central medial thalamus (ventral coordinate, $6.4 \mathrm{~mm}$ ), dorsal hypothalamus (ventral coordinate, $7.4 \mathrm{~mm}$ ), medial hypothalamus (ventral coordinate, $8.4 \mathrm{~mm}$ ), and basal hypothalamus (ventral coordinate, $9.4 \mathrm{~mm}$ ). Temperatures were also recorded $1 \mathrm{~mm}$ lateral to the midline $(2.3 \mathrm{~mm}$ posterior to bregma) in the laterodorsal thalamus (ventral coordinate, $5 \mathrm{~mm}$ ) and lateral hypothalamus (ventral coordinate, $8.4 \mathrm{~mm}$ ). Temperature measurements were taken at $1 \mathrm{~min}$ intervals, three times in each region. The same dorsoventral temperature gradients were observed independent of whether readings were made during lowering or raising the probe. Brain sites at various anteroposterior and mediolateral locations were chosen randomly. Core body temperature was also monitored and kept constant at $36^{\circ} \mathrm{C}$ (Harvard Instruments). At the end of each experiment, the brain was subjected to routine histological examination to verify the positions of the probes.

\section{RESULTS UCP2 mRNA in the brain}

Our goal was to examine UCP2 in the CNS. We first confirmed the presence of UCP2 mRNA in hypothalamic tissue fragments of rats (Fig. $1 A ; 4-6)$. In situ hybridization with a UCP2-specific, ${ }^{35}$ S-labeled riboprobe was then used to demonstrate that UCP2 mRNA is present in distinct hypothalamic nuclei. Labeled cells were localized in the hypothalamic paraventricular, supraoptic, suprachiasmatic, and arcuate nuclei (Fig. $1 C-E$ ).

\section{UCP2 protein in the brain}

We determined the localization of UCP2 protein in brain using an affinity-purified antiserum against human UCP2 that has been shown to react with UCP2 in skeletal muscle (Simoneau et al., 1998) and with recombinant expressed human UCP2 (data not shown). Western blots of brain extracts were used to characterize the antibody. A strong $23 \mathrm{kDa}$ band for UCP2 was detected by Western blot (Fig. 1B; 9). A fainter band at the predicted molecular weight of $33 \mathrm{kDa}$ was also apparent (Fig. $1 B$ ). The antibody does not cross-react with yeast expressing human UCP1, although there is a slight reactivity with yeast expressing human UCP3 (data not shown).

In spite of the fact that antibodies to UCP2 have a slight cross reactivity with $\mathrm{UCP} 3$, the UCP2 antibody can be used for immunohistochemistry in the brain because there is no UCP1 or UCP3 present. The overall distribution of UCP2-immunoreactive cell bodies agrees with the in situ hybridization results: the most impressive perikaryal labeling was in the supraoptic, paraventricular, suprachiasmatic, and arcuate nuclei of the hypothalamus (Fig. $1 F-I$ ). UCP2-containing axons were present in divergent hypothalamic and limbic sites corresponding to the projection fields of the regions where UCP2 mRNA and peptide were detected in neuronal cell bodies. These areas included the lateral septum, medial septum-diagonal band of Broca region, bed nucleus of the stria terminalis, organum vasculosum of the laminae terminalis, anteroventral periventricular area, medial preoptic area, periventricular regions, anterior hypothalamus, suprachiasmatic nucleus, retrochiasmatic area, supraoptic, paraventricular, arcuate, ventromedial, dorsomedial nuclei, lateral hypothalamus, external and internal layers of the median eminence, central and medial nucleus of the amygdala, and mediodorsal and paraventricular nuclei of the thalamus (Figs. $1 K, 2$ ). Immunoreactive profiles were also present in different brainstem nuclei (data not shown), including the parabrachial nucleus, area postrema, nucleus of the solitary tract, the spinotrigeminal tract, and to a lesser extent, the raphe, locus coeruleus, and dorsal motor root ganglion of the vagus. Immunolabeling for UCP2 was negligible in cortical regions, the hippocampal formation, and thalamic relay nuclei of ascending and descending cortical pathways (Fig. $1 K$ ).

Electron microscopy revealed that UCP2 immunolabeling was associated with the mitochondria and adjacent cytosol of neurons in all regions studied (Figs. 3, 4, 5C). Remarkably, although UCP2-containing mitochondria were detectable in all compartments of neurons, the vast majority of immunolabeled profiles were axons and axon terminals (Figs. 4, 5C). However, the synaptic vesicles seemed to be devoid of labeling (Figs. 4, 5C). UCP2-immunoreactive axon terminals established basket-like structures around the perikarya of postsynaptic neurons in different hypothalamic, limbic, and brainstem sites (Fig. $5 A, B$ ). Synapses between UCP2-containing axons and their postsynaptic targets were symmetrical (Figs. 4D, 5C). 
A

UCP2 mRNA

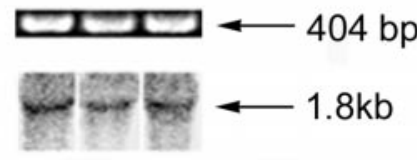

hypothalamus
B

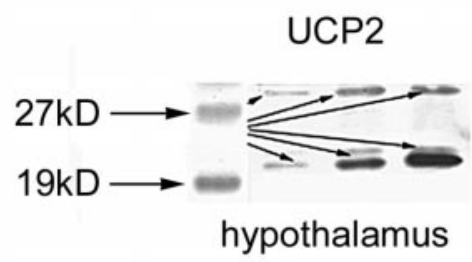

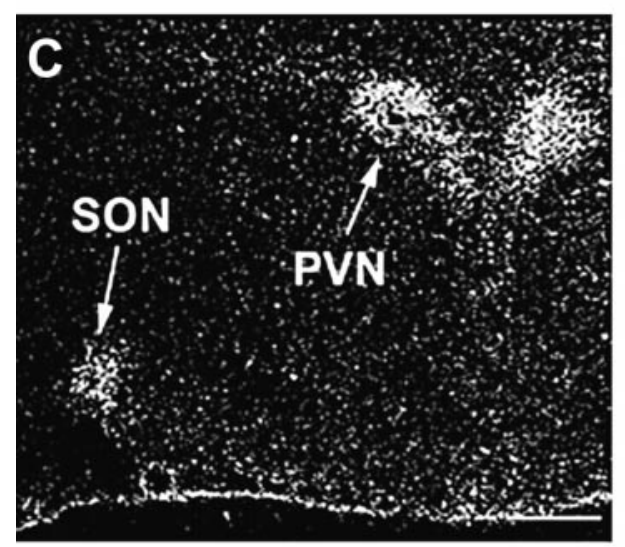
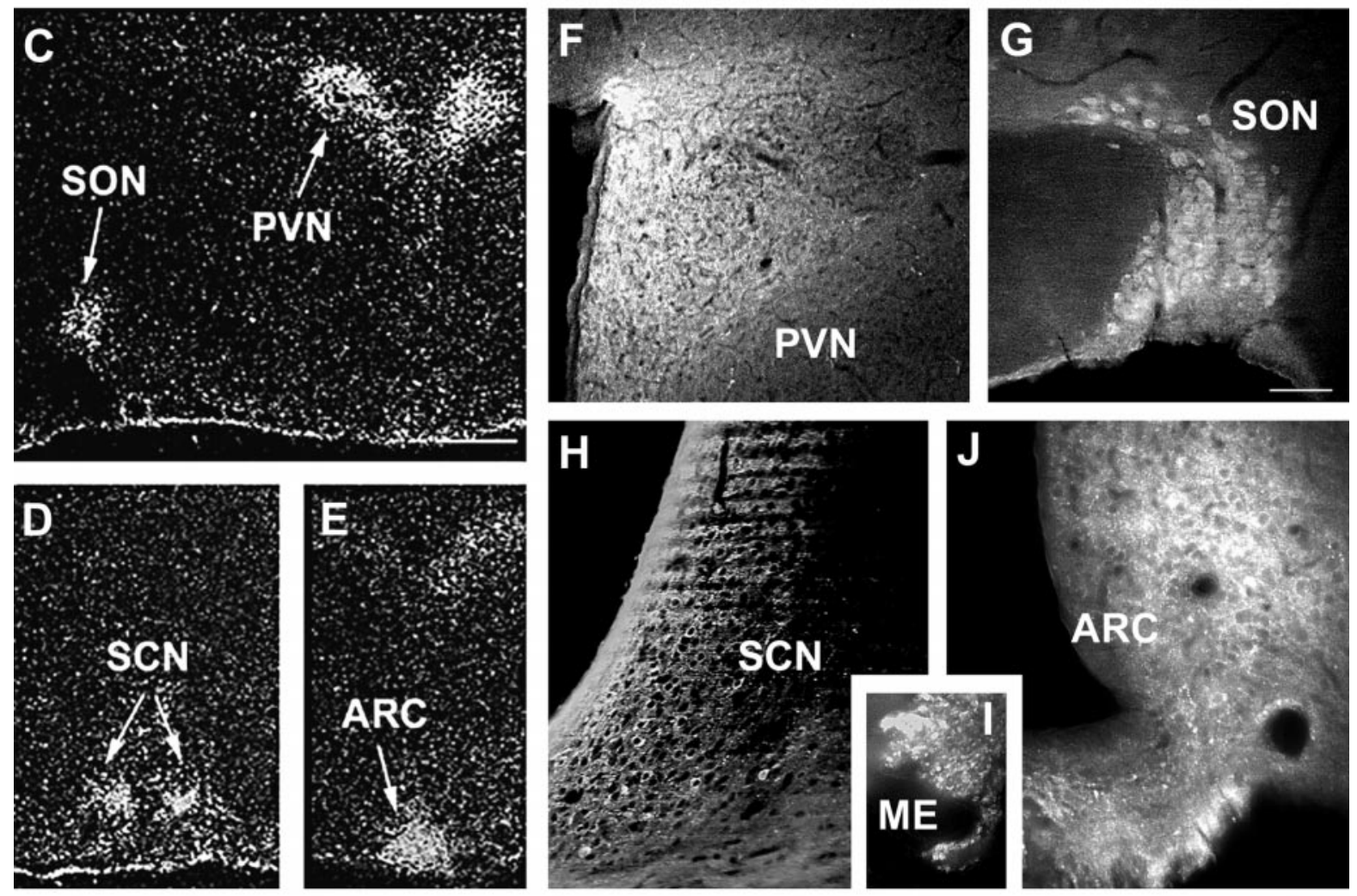

K
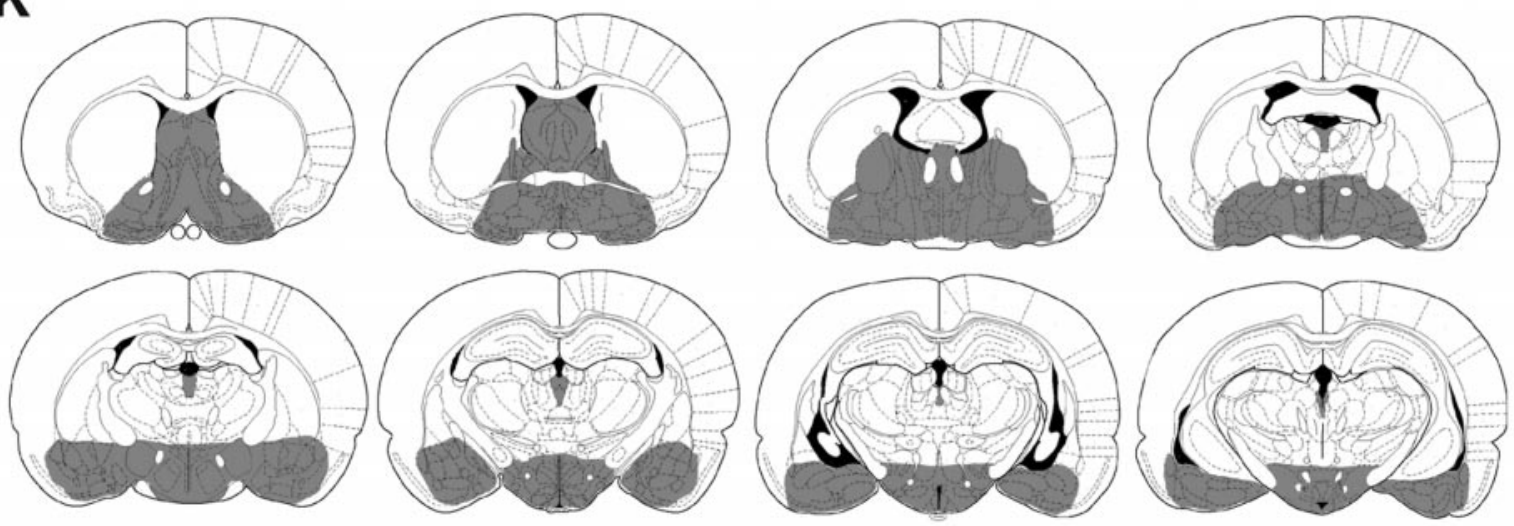

Figure 1. UCP2 mRNA and peptide expression in the brain. $A$, RT-PCR (top row) and Northern blot analyses of rat hypothalamic tissue demonstrates the expression of UCP2 mRNA. B, Western blot analysis of rat hypothalamic tissue revealed the expression of UCP2 peptide. Two major bands (arrows) were visible using the affinity-purified antisera: a band at $33 \mathrm{kDa}$ that corresponds to the predicted molecular weight of UCP2 and another strong band at $23 \mathrm{kDa}$ was also detected. $C-E$, In situ hybridization of UCP2 mRNA shows the concentration of labeled cells in four nuclei of the hypothalamus: the paraventricular $(P V N)$, supraoptic $(S O N)$, suprachiasmatic $(S C N)$, and arcuate nuclei $(A R C)$. F-I, Although immunolabeling for UCP2 in the rat hypothalamus resulted in perikarya labeling of cells in the nuclei that contained UCP2 mRNA (SON, PVN, SCN, ARC), labeled cellular processes were abundant throughout the hypothalamus. For example, the median eminence $(M E)$ that contains axonal fibers en route to the portal capillaries and the posterior lobe of the pituitary abundantly expressed UCP2. K, Schematic illustration (based on the rat brain atlas of Paxinos and Watson, 1997) of UCP2 (gray shaded areas) in the forebrain and diencephalon based on the in situ hybridization and immunocytochemistry studies. 

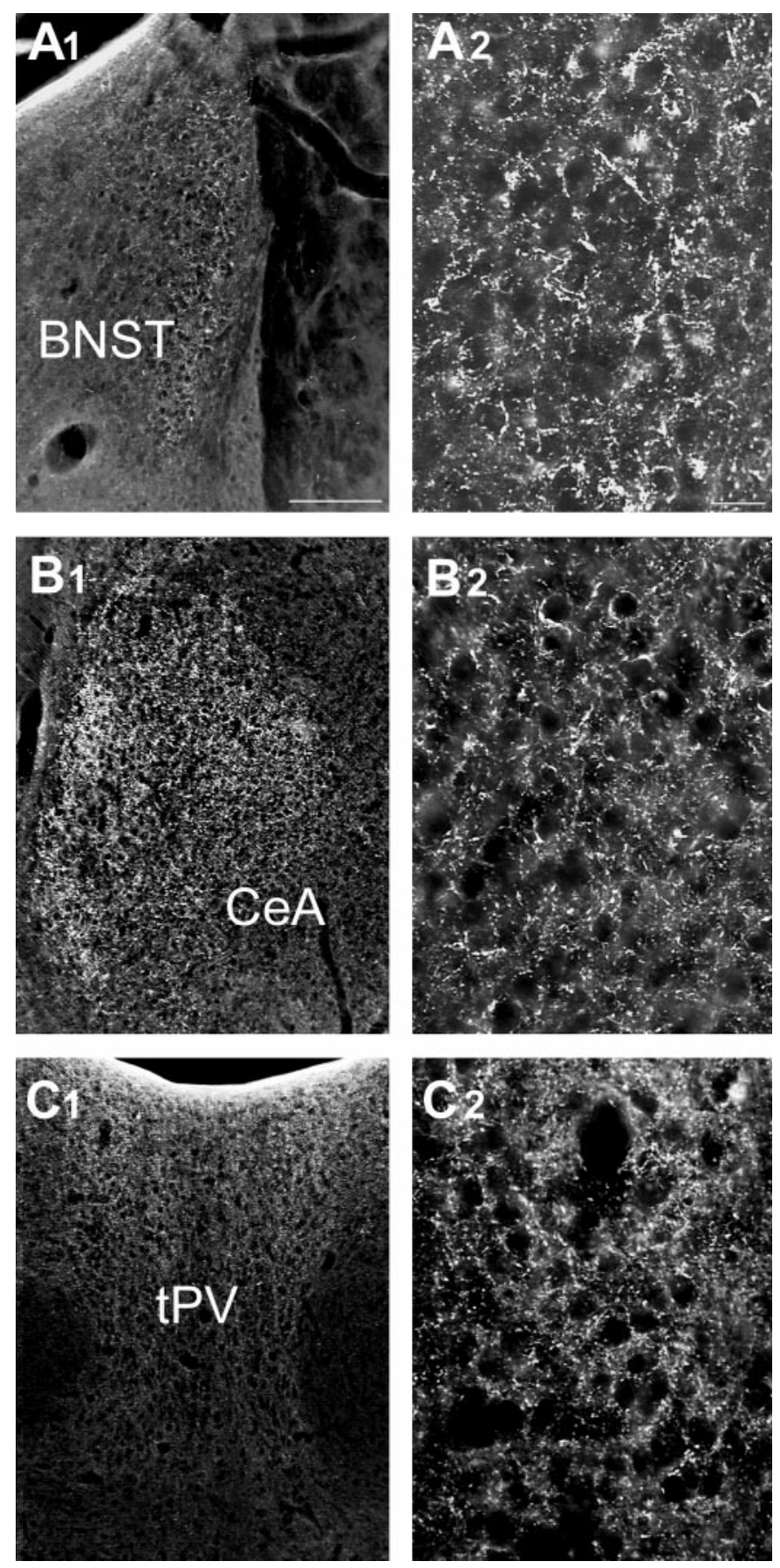

Figure 2. UCP2 in extrahypothalamic limbic sites. $A_{1}-C_{2}$, Light micrographs reveal the expression of UCP2 immunoreactivity in extrahypothalamic limbic sites. These areas included the bed nucleus of the stria terminalis $\left(B N S T ; A_{1}, A_{2}\right)$, the central nucleus of the amygdala $\left(C e A ; B_{1}\right.$, $\left.B_{2}\right)$, and the thalamic paraventricular nucleus $\left(t P V ; C_{1}, C_{2}\right)$. The higher power magnifications $\left(A_{2}, B_{2}, C_{2}\right)$ demonstrate the robust expression of UCP2 in neuronal processes in each of these areas. Scale bars: $A_{1}, 100$ $\mu \mathrm{m} ; A_{2}, 25 \mu \mathrm{m}$.

\section{Proton leak of brain mitochondria}

If UCP2 in the above-described neuronal circuits is a functional uncoupler in a manner similar to what was found in a yeast model (Fleury et al., 1997), the proton leak of mitochondria in UCP2containing brain regions should be increased. For that determination, we quantified mitochondrial coupling by measuring the

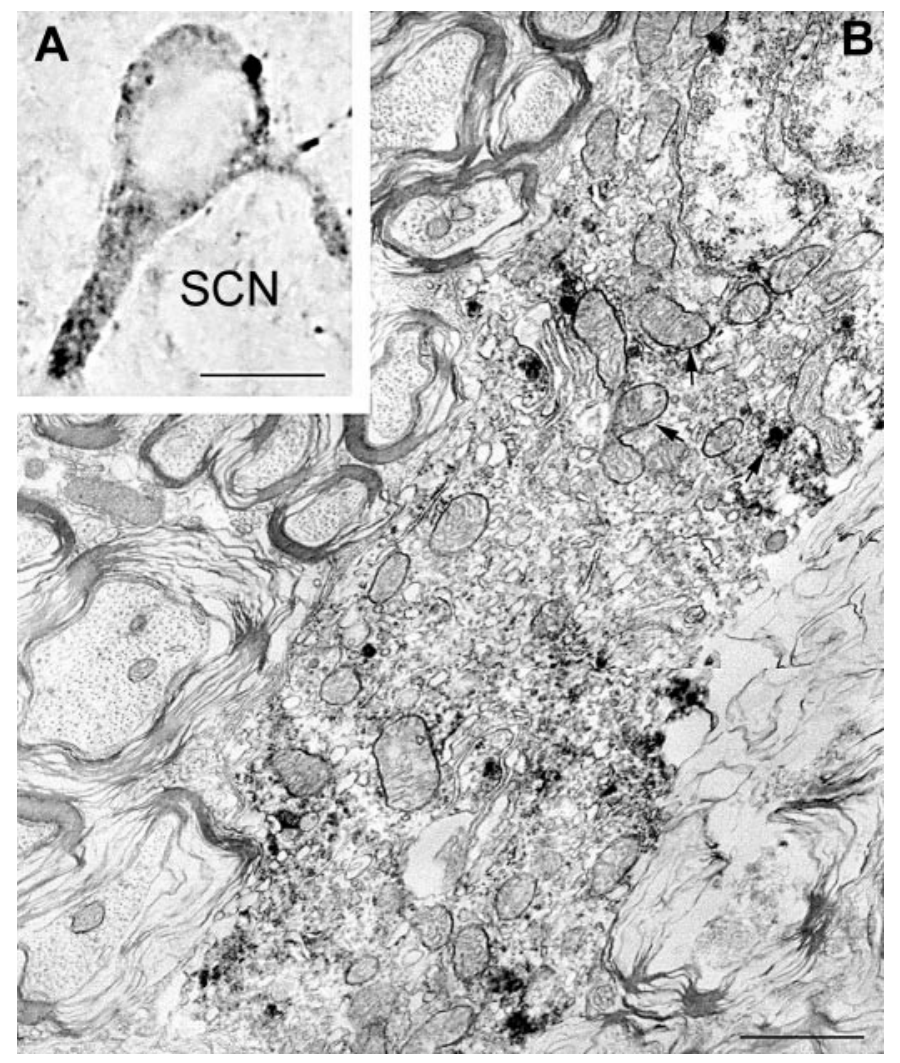

Figure 3. UCP2 in perikaryal mitochondria. Light $(A)$ and electron $(B)$ micrographs demonstrate UCP2 immunolabeling of perikaryal mitochondria (arrows) in the rat SCN. Immunoperoxidase is also associated with cytosol in close apposition to labeled mitochondria. Note the infolded nucleus of this SCN neuron. Scale bars: $A, 10 \mu \mathrm{m} ; B, 1 \mu \mathrm{m}$.

mitochondrial respiratory control ratio (RCR) in rat mitochondrial extracts from regions with abundant UCP2 expression (hypothalamus) and regions that lack UCP2 expression (the striatum-lateral thalamus region). The values observed in the striatum-lateral thalamus $(2.8 \pm 0.2$; Fig. $5 D)$ corresponded to earlier measurements taken from whole brains (Rolfe et al., 1994). However, the RCR value for extracts from the hypothalamus was significantly lower than the striatum-lateral thalamus $(2.1 \pm 0.1, p<0.05$; Fig. $5 D)$. The reduced RCR in the hypothalamus was attributable exclusively to an enhanced state 4 mitochondrial respiration rate (mitochondria respiring in the absence of ADP or nonphosphorylating mitochondria). State 4 respiration is caused only by the proton leak across the inner membrane. The values of state 4 respiration were significantly higher $(+32 \%)$ in hypothalamus $(45 \pm 3.4 \mathrm{nA} \mathrm{O} / \mathrm{min} \mathrm{mg}$ proteins) than in the striatum-lateral thalamus region $(34 \pm 3.0 \mathrm{nA}$ $\mathrm{O} / \mathrm{min} \mathrm{mg}$ proteins) $(p<0.05)$. On the other hand, state 3 mitochondrial respiration rate (phosphorylating mitochondria in which the respiration is not controlled by proton leak),measured in the two regions did not differ. The values for state 3 respiration were $95 \pm 3.7$ and $96 \pm 7 \mathrm{nA} \mathrm{O} / \mathrm{min} \mathrm{mg}$ proteins in the hypothalamus and striatum-lateral thalamus, respectively. These results demonstrate regional variations in uncoupling activity in which higher mitochondrial uncoupling activity is positively correlated with UCP2 expression.

\section{Cranial temperature measurements}

The presence of decreased mitochondrial energy coupling efficiency (increased proton leak) in UCP2-containing brain regions 

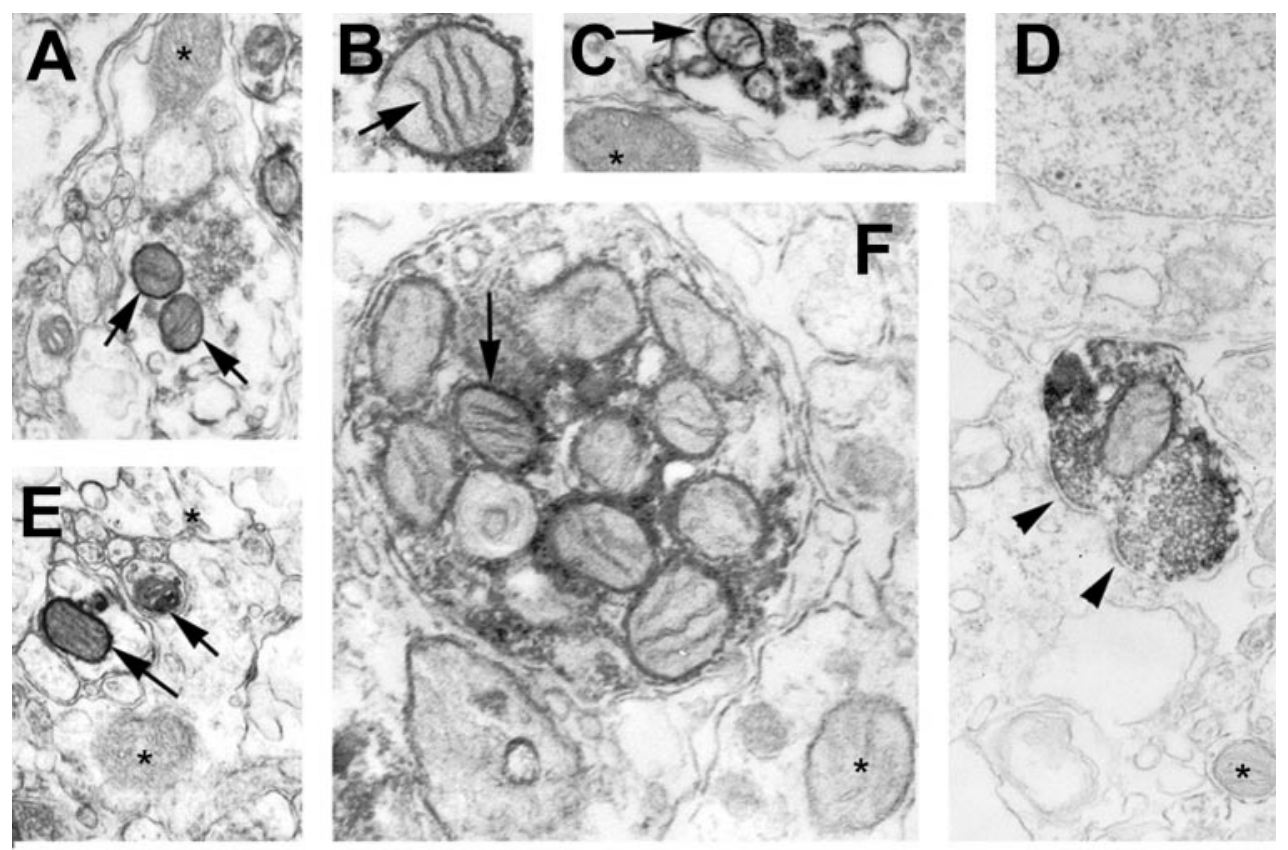

Figure 4. UCP2 in axonal mitochondria of the hypothalamus. $A-G$, Electron micrographs reveal the association of the UCP2 immunolabeling with mitochondria of different hypothalamic axons (arrows). Arrowheads in $D$ point to a symmetrical synapse established by a UCP2immunoreactive axon terminal in the arcuate nucleus. In $F$, note the abundance of UCP2-labeled mitochondria in an axon of the internal layer of the median eminence, which is the neuronal link between the magnocellular, paraventricular, and supraoptic nuclei and the posterior lobe of the pituitary. $G$, A large axon terminal containing UCP2-labeled mitochondria (arrows) in the external layer of the median eminence is in direct apposition to a portal capillary (cap), which provides the humoral link between the hypothalamus and the anterior pituitary. Asterisks indicate mitochondria with no UCP2 immunolabeling. Note that synaptic vesicles seem to be devoid of UCP2 labeling. Scale bar, $1 \mu \mathrm{m}$.
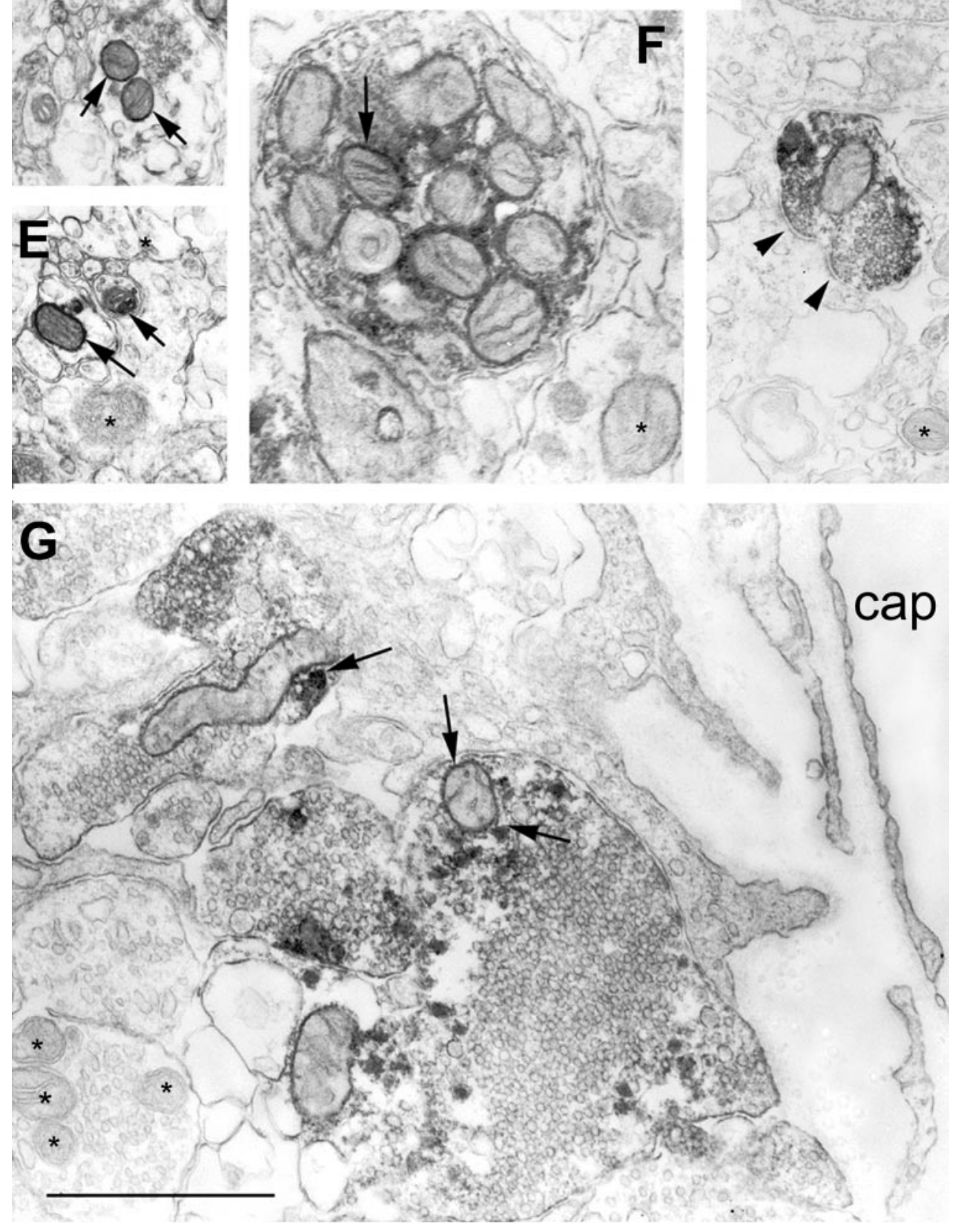

supports the hypothesis that a thermogenic mechanism is intrinsic to distinct neuronal pathways. To test this further, brain tissue temperature in the face of steady core body temperature was determined at several dorsoventral and mediolateral locations in the brains of anesthetized rats (Fig. 5E). Cortical temperature never reached $35^{\circ} \mathrm{C}$. Just lateral to the midline, temperatures of the dorsal thalamus and the central thalamus were $36.1 \pm 0.09^{\circ} \mathrm{C}$ and $36.3 \pm 0.12^{\circ} \mathrm{C}$, respectively. The more ventrally located hypothalamic nuclei displayed significantly higher temperatures $\left(37.1 \pm 0.09^{\circ} \mathrm{C} ; p<0.01\right)$. However, there was only a small temperature gradient within the hypothalamus along a $2 \mathrm{~mm}$ dorsoventral extent. The significant increase in diencephalic tem- perature coincided with the appearance of UCP2 immunoreactivity in the dorsal hypothalamus (Fig. 5E). A dorsoventral temperature gradient was also found further lateral to the midline. Temperatures of the laterodorsal thalamus and the lateral hypothalamus were $36.3 \pm 0.10^{\circ} \mathrm{C}$ and $36.9 \pm 0.05^{\circ} \mathrm{C}$, respectively. These temperatures were recorded at $36.0^{\circ} \mathrm{C}$ rectal (core) temperature. There was no change in rectal temperature during the intracranial measurements. Comparison of cranial temperature values from different sites in the brain versus the core body temperature revealed significant differences between the hypothalamic values and the core body temperature (Fig. 5E). 

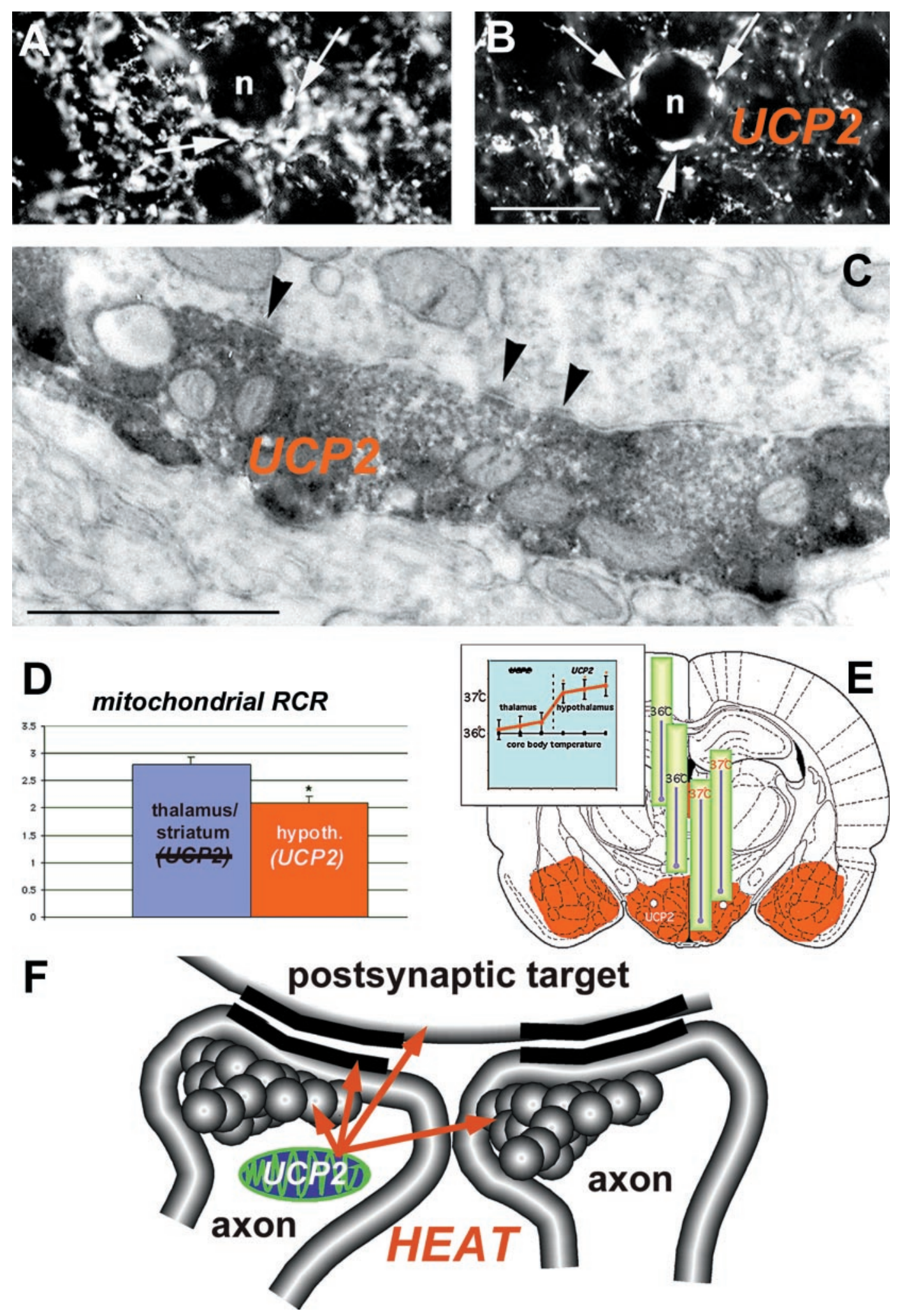

Figure 5. Brain UCP2 in axons predicts increased mitochondrial proton leak and heat production. Light $(A, B)$ and electron $(C)$ micrographs demonstrate the abundant expression of UCP2 in presynaptic axon terminals. Arrows on the light micrographs of $A$ and $B$ point to UCP2-containing presynaptic terminals in the central amygdaloid nucleus that establish symmetrical synapses ( $C$, arrowheads) on the postsynaptic target. $D$, The measurement of mitochondrial respiration in brain regions (left panel) where UCP2 is present (hypothalamus) and where no UCP2 was detected (thalamus/striatum) showed a lower mitochondrial phosphorylation level (lower RCR) in the hypothalamus that was caused exclusively by an increased proton leak of mitochondria in UCP2-containing regions. E, In agreement with this increased mitochondrial uncoupling activity, brain temperature in the UCP2-expressing hypothalamus was significantly higher than that of the thalamus (right panel) and the core body temperature. $F$, The presence of UCP2 in axon terminals together with the significant, positive correlation between UCP2 and mitochondrial uncoupling and local brain temperature suggests that heat produced presynaptically by UCP2 may have a direct influence on axonal temperature leading to the modulation of presynaptic and postsynaptic events. 
Figure 6. UCP2 in hypothalamic peptidergic circuits. Fluorescence double labeling using heterologous antisera revealed UCP2 immunoreactivity (left panels, green fluorescence) in paraventricular neurons producing CRF (top right panel, red fluorescence; arrows point to the double-immunolabeled cells in $A_{1}$ and $A_{2}$ ), in CRF-containing axon terminals in the external layer of the median eminence $\left(B_{1}, B_{2}\right)$, in NPY-containing arcuate nucleus neurons $\left(C_{1}, C_{2}\right)$, and in VPexpressing cells of the supraoptic nucleus $\left(D_{1}, D_{2}\right)$.

Figure 7. Relationship between UCP2 and neuronal circuits involved in endocrine and metabolic regulation. $A_{1}-A_{3}$, Green fluorescent UCP2-immunoreactive axon terminals $\left(A_{1}\right.$, red arrowheads) in close proximity to an arcuate nucleus neuron expressing immunoreactivity for receptor of the peripheral metabolic hormone leptin (ObR; $\left.A_{2}\right)$. The image of $A_{3}$ was taken using filters sensitive for both red and green fluorescence. $B_{1}-B_{3}$, Green fluorescent, UCP2-immunoreactive perikaryonin the arcuate nucleus containing labeling for the peripheral sex hormone estradiol (ER; red fluorescence). $C_{1}-C_{3}$, Green fluorescent UCP2-immunoreactive axon terminals (red arrowheads) in close proximity to a perikaryon of the dorsomedial hypothalamic nucleus $(D M N)$ that was activated by fasting (red fluorescent, nuclear c-fos labeling). Fasting-induced c-fos expression was also detected in the lateral hypothalamusperifornical region, arcuate nucleus, medial preoptic area, central amygdaloid nucleus, and the paraventricular thalamic nucleus. $D_{1}-$ $D_{4}$, Green fluorescent UCP2-producing parvicellular neurons of the paraventricular nucleus $\left(P V N ; D_{l}\right.$, arrows) are neuroendocrine as revealed by retrograde tracing from the periphery using fluorogold $\left(D_{2}, F G\right.$; FG labeling vas visualized using transillumination with ultraviolet light). The UCP2-expressing neuroendocrine cell located to the right $\left(D_{3}\right.$, $D_{4}$, green arrows) also contains leptin receptors $\left(\mathrm{ObR} ; \mathrm{D}_{3}\right.$, red fluorescence). $\mathrm{E}$, Red fluorescent, UCP2-containing axon terminals (red arrows) in close proximity to a neuronal perikaryon (green arrowhead) in the lateral hypothalamus $(L H)$ that expresses the appetite-inducing peptide orexin. $F$, Red fluorescent, UCP2-containing axon terminals (red arrows) in close proximity to a hypophyseotropic neuron that produce luteinizing hormone-releasing hormone $(L H R H)$ in the medial preoptic region (MPO). $G$, Green fluorescent UCP2-immunoreactive axon terminals (red arrowheads) in close proximity to a perikaryon of MPO that was activated by cold exposure (red fluorescent, nuclear c-fos labeling). Other cold-activated neurons were distributed in the paraventricular nucleus, medial preoptic area, bed nucleus of the stria terminalis, central amygdaloid nucleus, and the paraventricular thalamic nucleus.
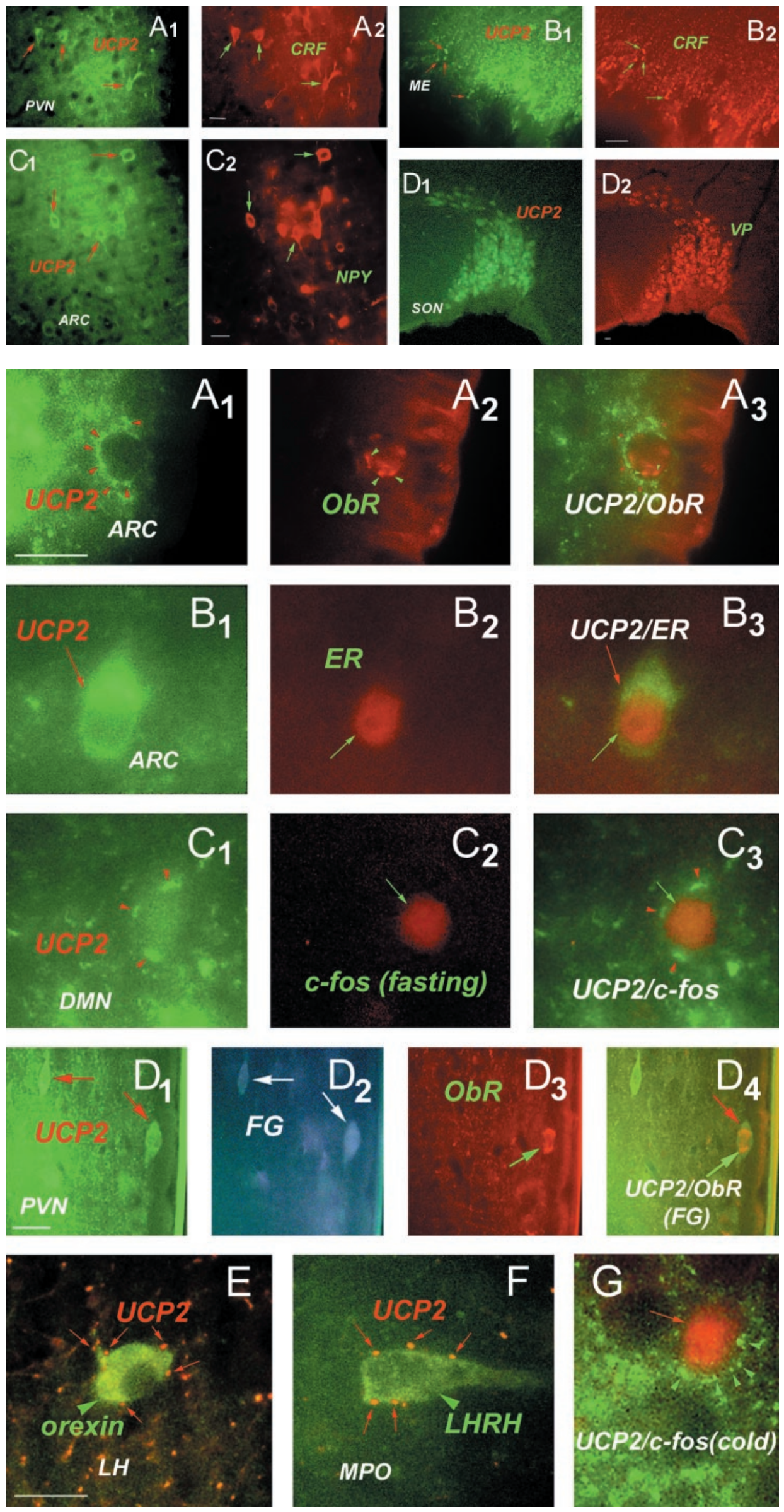


\section{UCP2 in neuronal circuits involved in homeostatic regulation}

We explored the relationship between UCP2 and different brain receptors for peripheral hormones, hypothalamic peptidergic systems involved in autonomic metabolic and endocrine regulation, and neuronal pathways that are activated by fasting or cold exposure by multiple-label immunocytochemical experiments (Figs. 6, 7).

In the rat, bright-field and fluorescent microscopy revealed that UCP2 is coexpressed with CRF in neurons of the parvicellular region of the paraventricular nucleus, with $\mathrm{VP}$ and, to a lesser extent, OX in neurons of the supraoptic nucleus, and with NPY in neurons of the arcuate nucleus (Fig. 6). These systems are known to regulate behavioral and hormonal aspects of metabolism, are present in the hypothalamus and brainstem, but do not send extended projections to higher brain regions. No UCP2 immunolabeling was present in lateral hypothalamic melaninconcentrating hormone $(\mathrm{MCH})$ or hypocretin/orexin (HCRT)containing cells that are important regulators of feeding behavior and are known to send projections to the cerebral cortex and the hippocampus (Qu et al., 1996; de Lecea et al., 1998; Sakurai et al., 1998). On the other hand, all of the aforementioned hypothalamic neuronal populations as well as those expressing the hypophyseotropic hormone LHRH (Fig. 7F) were targeted by UCP2containing axon terminals. Populations of UCP2-producing neuronal perikarya expressed receptors for the metabolic hormone leptin (ObR; Fig. $7 D_{1}-D_{4}$ ), estrogen receptors (ER; Fig. $7 B_{1}-B_{3}$ ) or androgen receptors (AR) in the arcuate nucleus. Frequently, UCP2-immunolabeled axons and axon terminals were also in close proximity to ObR- (Fig. $7 A_{1}-A_{3}$ ) or ER-immunolabeled, putative postsynaptic targets. Populations of UCP2-labeled cells in the hypothalamus were retrogradely labeled with peripherally injected fluorogold (FG) (Fig. $\left.7 D_{1}-D_{4}\right)$. This indicates that populations of UCP2-producing neurons project to portal capillaries of the median eminence and to the posterior lobe of the pituitary, and hence, they are neuroendocrine cells. Some of these neuroendocrine UCP2-producing cells also expressed ObR (Fig. $\left.7 D_{1}-D_{4}\right)$.

After analysis of those hypothalamic pathways that were activated either by fasting or cold exposure, neurons containing c-fos induced by either of these manipulations were massively innervated by UCP2-containing axon terminals (Fig. $7 C_{1}-C_{3}$ ). In fasted rats, c-fos expression was detected in the lateral hypothalamus-perifornical region, arcuate nucleus, dorsomedial nucleus, paraventricular nuclei, medial preoptic area, central amygdaloid nucleus, and the paraventricular thalamic nucleus. While fasting-induced changes in the number of c-fos-expressing cells differed in the different subnuclei (data not shown), all of the (100\%) 3654 c-fos-expressing cells counted in the basal brain of five fasted rats received multiple inputs expressing UCP2 (Fig. $7 C_{1}-C_{3}$ ). In cold-exposed rats, c-fos-expressing cells were distributed in the paraventricular nucleus, medial preoptic area, bed nucleus of the stria terminalis, central amygdaloid nucleus, and the paraventricular thalamic nucleus. Similar to what was found after fasting, all $(100 \%)$ of the cold-activated, c-fos-expressing cells (1765) were contacted by numerous UCP2-containing axon terminals (Fig. $7 G$ ).

\section{DISCUSSION}

\section{UCP2 in brain thermogenesis}

Temperature differences in various brain regions have been observed in rodents and more recently in humans, by invasive and noninvasive techniques (Mellergard and Nordstrom, 1990; Andersen and Moser, 1995; Moser and Mathiesen, 1996; Corbett et al., 1997; Schwab et al., 1997). Consistent with these studies, intracranial temperature measurements in the present study revealed a dorsoventral temperature gradient, where the most ventral brain regions displayed the highest temperature. Interestingly, however, this temperature gradient did not develop in a linear fashion. Instead, the occurrence of UCP2 and the increased proton leak in mitochondria coincided with this dorsoventral temperature gradient, indicating that UCP2-mediated mitochondrial uncoupling might contribute to this phenomenon. Because neuronal activity might be only a minor factor in neural thermogenesis (Erickson et al., 1996), and hypothalamic temperature significantly exceeded the core body temperature, the uncoupling of oxidative phosphorylation from ATP synthesis may be an important mechanism in heat production by brain.

\section{UCP2 in thermoregulation}

In a recent study, Richard et al. (1998) revealed an abundant expression of UCP 2 mRNA in mainly basal structures of the mice brain as well. Although it may be that some species differencesexist in brain UCP2 expression, it is reasonable to suggest that brain UCP2 may represent an intracellular mechanism that is conserved over mammalian evolution. In fact, it is not surprising that the hypothalamus is a tissue with apparent thermogenic activity, because normal neuronal function in autonomic and endocrine centers would be preserved by thermogenic buffering, regardless of environmental temperature. For example, the abundant expression of UCP2 in the suprachiasmatic nucleus may explain the resistance of the biological clock to fluctuating peripheral temperature (Burgoon and Boulant, 1998). Furthermore, many of the hypothalamic nuclei, including the preoptic area, that express UCP2 are known to participate in the regulation of body temperature. In support of the involvement of brain UCP2 in thermoregulatory responses, we found that all of those cells that expressed c-fos after cold exposure received a robust input by UCP2-containing axons. Interestingly, cold exposure has been found to induce the thermogenic coactivator PGC-1, which is also expressed in the brain (Puigserver et al., 1998), and was shown to trigger adaptive thermogenesis, at least in part, via the regulation of UCP2 (Wu et al., 1999). Whether brain UCP2 levels contribute to the ability to adopt to fluctuating ambient temperature and influence thermoregulatory processes by changing local brain temperature is an intriguing question that deserves further investigation.

\section{UCP2 affecting neuronal activity}

Taking into account that the majority of UCP2 was localized to axons and axon terminals, the novel concept is proposed that in distinct brain circuits, synapses may exist in which heat is produced to modulate neurotransmission (Fig. $5 F$ ). It may seem surprising that a mechanism directly related to heat production in peripheral tissues under the apparent control of the thermogenic coactivator PGC-1 (Wu et al., 1999) is present in predominantly glucose-utilizing (Oomura, 1983) neuronal populations, particularly in axon terminals of the CNS. However, because neurotransmission is a highly energy-dependent process (Laughlin et al., 1998), the significance of a mitochondrial uncoupling mechanism in neuronal processes becomes evident. First, acute heat production in axon terminals could immediately accelerate synaptic transmission by affecting synaptic vesicle formation and traffic, neurotransmitter release and reuptake, and the tertiary structure 
of neuromodulators as well as directly influence the postsynaptic membrane potential (Fig. $5 F$ ). On the other hand, chronic uncoupling of the oxidative chain in neuronal mitochondria may diminish available ATP, thereby compromising neuronal functions. This latter possibility could provide a clue as to how brain circuits may be shut down during hibernation. In addition, by increasing the efficacy of the oxidative chain, uncoupling proteins could readily decrease the amount of reactive oxygen species and consequent degenerative processes in neurons (Negre-Salvayre et al., 1997; Korshunov et al., 1998; Richard et al., 1998).

The present study showed that brain sites other than those containing UCP2, such as the striatum and thalamus, also show significant mitochondrial proton leak. Temperature elevations in association with increased neuronal activity were also observed in the hippocampus and cerebral cortex (Andersen and Moser, 1995; Erickson et al., 1996), where UCP2 is absent. These observations are consistent with several hypotheses, including one that there may be additional brain uncouplers. In fact, a brain mitochondrial carrier protein (BMCP1) and a brain-specific uncoupling protein, $\mathrm{UCP} 4$, with respiration uncoupling activity in yeast and mammalian cells, respectively, were recently discovered, and their mRNA was localized to diverse structures of the brain, including the cerebral cortex and hippocampal formation (Sanchis et al., 1998; Mao et al., 1999). Thus, the concept that synaptic transmission is modulated by heat produced locally in axon terminals may represent a general phenomenon in the CNS.

\section{UCP2 in homeostatic centers}

Even though other neuronal and glial uncouplers may be discovered, the intriguing feature of brain UCP2 expression is that, unlike BMCP1 and UCP4, UCP2 was present predominantly in neuronal populations of subcortical regions that are involved in the central regulation of autonomic, endocrine, and metabolic processes. In agreement with the known projection fields of the paraventricular, supraoptic, suprachiasmatic, and arcuate nuclei where UCP2-producing perikarya were located, there was very minimal UCP2 in axonal processes of the cerebral cortex and hippocampus. This observation suggests that the selective regulation of UCP2 may influence homeostatic regulation without directly affecting higher brain functions. The assertion that the $\mathrm{UCP} 2$ input of neurons in the CNS is of significance can be inferred from the fact that UCP2 boutons predominantly established basket-like structures around neuronal perikarya. Because it is on the perikaryon where axon terminals can affect the postsynaptic target with the most efficacy, the UCP2 network, when activated, could readily modulate and coordinate the activity of central homeostatic circuits.

The robust expression of UCP2 in neuronal processes of the hypothalamo-neurohypophyseal and adenohypophyseal systems suggests that a mitochondrial thermogenic mechanism participates in the regulation of vasopressin and oxytocin release in the posterior pituitary and the secretion of CRF into the portal vessels in the external layer of the median eminence. Thus, in future experiments in which selective regulation of UCP2 will be achieved, the role of UCP2 in water homeostasis, lactation, and the activity of the hypothalamo-pituitary-adrenal axis will be able to be determined.

The abundant coexpression of UCP2 and NPY in the arcuate nucleus indicates that acute activation of UCP2 by peripheral signals could readily affect the activity of this key hypothalamic peptidergic system that was shown to be crucial for feeding behavior and endocrine regulation (for review, see Kalra and
Horvath 1998; Kalra et al., 1999). In further support of the involvement of UCP2 in central metabolic pathways, UCP2 cells and processes were closely associated with leptin receptors, and all of the c-fos-expressing neurons after fasting were targeted by numerous UCP2-containing boutons. In accordance with the projection of arcuate nucleus neurons, UCP2-containing axons were found to innervate other hypothalamic peptidergic systems, including $\mathrm{MCH}$ - and orexin-producing cells, that participate in metabolic regulation (for review, see Kalra et al., 1999) but, themselves, did not produce UCP2. Because arcuate nucleus NPY neurons are known to project to the vicinity of these cells, and synaptic interaction between NPY and orexin has been reported (Horvath et al., 1999), it is likely that the UCP2 input of $\mathrm{MCH}$ and orexin cells contain NPY. To confirm this, it will be important to determine whether UCP2 is coexpressed with agouti-related peptide (AGRP) in these axon terminals; AGRP is an orexigenic peptide that is produced exclusively in arcuate nucleus NPY cells (Ollmann et al., 1997; Hahn et al., 1998). It should be emphasized that because of the predominant expression of UCP2 in axonal processes, colocalization experiments using double-labeling in situ hybridization will yield a deeper insight into the coexpression of UCP2 with other hypothalamic peptides and neurotransmitters. In this regard, note that UCP2expressing cells were also located in lateral regions of the arcuate nucleus where NPY cells are not present, but opiate neurons are abundant.

While it is known that there are hypothalamic peptidergic circuits, such as the opiate, NPY, and orexin cells, that participate in the regulation of divergent hypothalamic functions (Elmquist et al., 1999; Kalra and Horvath, 1998; Kalra et al., 1999), it was apparent that UCP2 axons also innervated neurons of the hypothalamus that are predominantly associated with endocrine regulation. These postsynaptic targets included gonadal steroid receptor-containing cells as well as the LHRH cells that are final output neurons in the central regulation of pituitary gonadotropins. Because of the abundance of UCP2-containing axon terminals in the hypothalamus, it can be expected that other hypophyseotropic and non-hypophyseotropic cells of the hypothalamus are associated with the UCP2-containing neuronal network.

In summary, we have shown that UCP2 is expressed in neurons involved in the regulation of homeostasis in brain regions with the highest proton leak and thermogenesis. UCP2 expression in mitochondria of neurons, particularly in axon terminals, suggests that a mitochondrial uncoupling/thermogenic mechanism plays a direct role in interneuronal communication in circuits involved in the central regulation of homeostasis. Thus, UCP2 in the many neuronal networks regulating body weight may coordinate the behavioral, autonomic, and endocrine responses to a changing environment.

\section{REFERENCES}

Andersen P, Moser EI (1995) Brain temperature and hippocampal function. Hippocampus 5:491-498.

Boss O, Muzzin P, Giacobino JP (1998) The uncoupling proteins, a review. Eur J Endocrinol 139:1-9.

Boss O, Samec S, Paoloni-Giacobino A, Rossier C, Dulloo A, Seydoux J, Muzzin P, Giacobino JP (1997) Uncoupling protein-3: a new member of the mitochondrial carrier family with tissue-specific expression. FEBS Lett 408:39-42.

Bouillaud F, Ricquier D, Thibault J, Weissenbach J (1985) Molecular approach to thermogenesis in brown adipose tissue: cDNA cloning of the mitochondrial uncoupling protein. Proc Natl Acad Sci USA 82:445-448.

Burgoon PW, Boulant JA (1998) Synaptic inhibition: its role in supra- 
chiasmatic nucleus neuronal thermosensitivity and temperature compensation in the rat. J Physiol (Lond) 512:793-807.

Campfield LA, Smith FJ, Guisez Y, Devos R, Burn P (1995) Recombinant mouse $\mathrm{OB}$ protein: evidence for a peripheral signal linking adiposity and central neural networks. Science 269:546-549.

Corbett R, Laptook A, Weatherall P (1997) Noninvasive measurements of human brain temperature using volume-localised proton magnetic resonance spectroscopy. J. Cereb Blood Flow Metab 17:363-367.

de Lecea L, Kilduff TS, Peyron C, Gao XB, Foye PE, Danielson PE, Fukuhara C, Battenberg ELF, Gautvik VT, Bartlett II FS, Frankel WN, van den Pol AN, Bloom FE, Gautvik KM, Sutcliffe JG (1998) The hypocretins: two hypothalamic peptides with neuroexcitatory activity. Proc Natl Acad Sci USA 95:322-327.

Elmquist JK, Elias CF, Saper CB (1999) From lesions to leptin: hypothalamic control of food intake and body weight. Neuron 2:221-232.

Erickson CA, Jung MW, McNaughton BL, Barnes CA (1996) Contribution of single-unit spike waveform changes to temperature-induced alterations in hippocampal population spikes. Exp Brain Res 107:348-360.

Fleury C, Neverova M, Collins S, Raimbault S, Champigny O, LeviMeyrueis C, Bouillaud F, Seldin MF, Surwit RS, Ricquier D, Warden $\mathrm{CH}$ (1997) Uncoupling protein-2: a novel gene linked to obesity and hyperinsulinemia. Nat Genet 15:269-272.

Friedman JF, Halaas JL (1998) Leptin and the regulation of body weight in mammals. Nature 395:763-771.

Gong DW, He Y, Karas M, Reitman M (1997) Uncoupling protein-3 is a mediator of thermogenesis regulated by thyroid hormone, beta3adrenergic agonists, and leptin. J Biol Chem 272:24129-24132.

Gura T (1998) Uncoupling proteins provide new clue to obesity's causes. Science 280:1369-1370.

Hahn TM, Breininger JF, Baskin DG, Schwartz MW (1998) Coexpression of Agrp and NPY in fasting-activated hypothalamic neurons. Nat Neurosci 1:271-272.

Halaas JL, Gajiwala KS, Maffei SL, Cohen BT, Chaib D, Rabanowitz RL, Lallone SK, Burley SK, Friedman JM (1995) Weight-reducing effects of the plasma protein encoded by the obese gene. Science 269:543-546.

Horvath TL (1997) Suprachiasmatic efferents avoid phenestrated capillaries but innervate neuroendocrine cells including those producing dopamine. Endocrinology 138:1312-1320.

Horvath TL (1998) An alternate pathway for visual signal integration into the hypothalamo-pituitary axis: retinorecipient intergeniculate neurons project to various regions of the hypothalamus and innervate neuroendocrine cells including those producing dopamine. J Neurosci 18:1546-1558.

Horvath TL, Bechmann I, Kalra SP, Naftolin F, Leranth C (1997) Heterogeneity in the neuropeptide $\mathrm{Y}$-containing neurons of the rat arcuate nucleus: GABAergic and non-GABAergic subpopulations. Brain Res 756:283-286.

Horvath TL, Diano S, van den Pol AN (1999) Synaptic interaction between hypocretin (orexin) and neuropeptide Y cells in the rodent and primate hypothalamus: a novel circuit implicated in metabolic and endocrine regulations. J Neurosci 1:1072-1087.

Kalra SP (1997) Appetite and body weight regulation: is it all in the brain? Neuron 19:227-230.

Kalra SP, Horvath TL (1998) Neuroendocrine interactions between galanin, opioids, and neuropeptide $\mathrm{Y}$ in the control of reproduction and appetite. Annals of the NY Acad Sci 863:236-240.

Kalra SP, Xu B, Dube MG, Pu S, Horvath TL, Kalra PS (1999) Interacting appetite regulating pathways in the hypothalamic regulation of body weight. Endocr Rev 20:67-100.

Klaus S, Casteilla L, Bouillaud F, Ricquier D (1991) The uncoupling protein UCP: a membraneous mitochondrial ion carrier exclusively expressed in brown adipose tissue. Int J Biochem 9:791-801.

Korshunov SS, Korkina OV, Ruuge EK, Skulachev VP, Starkov AA (1998) Fatty acids as natural uncouplers preventing generation of O2.and $\mathrm{H} 2 \mathrm{O} 2$ by mitochondria in the resting state. FEBS Lett 435:215-218.

Laloi M, Klein M, Riesmeier JW, Muller-Rober B, Fleury C, Bouillaud F, Ricquier D (1997) A plant cold-induced uncoupling protein. Nature 389:135-136.

Laughlin SB, de Ruyter van Stevenick RR, Anderson JC (1998) The metabolic cost of neuronal information. Nat Neurosci 1:436-441.

Liu Q, Bai C, Chen F, Wang R, MacDonald T, Gu M, Zhang Q, Morsy
MA, Caskey CT (1998) Uncoupling protein-3: a muscle-specific gene upregulated by leptin in ob/ob mice. Gene 207:1-7.

Lombardi A, Lanni A, Moreno M, Brand MD, Goglia F (1998) Effect of 3,5-di-iodo-L-thyronine on the mitochondrial energy-transduction apparatus. Biochem J 330:521-526.

Mao W, Yu XX, Zhong A, Li W, Brush J, Sherwood SW, Adams SH, Pan G (1999) UCP4, a novel brain-specific mitochondrial protein that reduces membrane potential in mammalian cells. FEBS Lett 443:326-330.

Mellergard P, Nordstrom C-H (1990) Epidural temperature and possible intracerebral temperature gradients in man. Br J Neurosurg 4:31-38.

Moser EI, Mathiesen I (1996) Relationship between neuronal activity and brain temperature in rats. NeuroReport 7:1876-1880.

Negre-Salvayre A, Hirtz C, Carrera G, Cazenave R, Troly M, Salvayre R, Penicaud L, Casteilla L (1997) A role for uncoupling protein-2 as a regulator of mitochondrial hydrogen peroxide generation. FASEB J 11:809-815.

Nicholls DG, Locke RM (1984) Thermogenic mechanism in brown fat. Physiol Rev 64:1-64.

Ollmann MM, Wilson BD, Yang YK, Kerns JA, Chen Y, Gantz I, Barsh GS (1997) Antagonism of central melanocortin receptors in vitro and in vivo by agouti-related protein. Science 278:135-138.

Oomura Y (1983) Glucose as a regulator of neuronal activity. Adv Metab Disord 10:31-65.

Paxinos G, Watson C (1997) The rat brain in stereotaxic coordinates. San Diego, CA: Academic.

Pelleymounter MA, Cullen MJ, Baker MB, Hecht R, Winters D, Boone T, Collins F (1995) Effects of the obese gene product on body weight regulation in ob/ob mice. Science 269:540-543.

Puigserver P, Wu Z, Park CW, Graves R, Wright M, Spiegelman M (1998) A cold-inducible coactivator of nuclear receptors linked to adaptive thermogenesis. Cell 92:829-839.

Qu D, Ludwig DS, Gammeltoft S, Piper M, Pelleymounter MA, Cullen MJ, Mathes WF, Pryzpek J, Kanarek R, Maratos-Flier E (1996) A role for melanin-concentrating hormone in the central regulation of feeding behavior. Nature 380:243-247.

Richard D, Rivest R, Huang Q, Bouillaud F, Sanchis D, Champigny O, Ricquier D (1998) Distribution of the uncoupling protein 2 mRNA in the mouse brain. J Comp Neurol 397:549-560.

Rolfe DF, Hulbert AJ, Brand MD (1994) Characteristics of mitochondrial proton leak and control of oxidative phosphorylation in the major oxygen-consuming tissues of the rat. Biochim Biophys Acta 1188:405-416.

Sakurai T, Amemiya A, Ishii M, Matsuzaki I, Chemelli RM, Tanaka H, Williams SC, Richardson JA, Kozlowski GP, Wilson S, Arch JRS, Buckingham RE, Haynes AC, Carr SA, Annan RS, McNulty DE, Liu W-S, Terrett JA, Elshourbagy NA, Bergsma DJ, Yanagisawa M (1998) Orexins and orexin receptors: a family of hypothalamic neuropeptides and $\mathrm{G}$ protein-coupled receptors that regulate feeding behavior. Cell 92:573-585.

Samec S, Seydoux J, Dulloo AG (1998) Role of UCP homologues in skeletal muscles and brown adipose tissue: mediators of thermogenesis or regulators of lipids as fuel substrate? FASEB J 12:715-724.

Sanchis D, Fleury C, Chomiki N, Goubern M, Huang Q, Neverova M, Gregiore F, Easlick J, Raimbault S, Levi-Meyrueis C, Miroux B, Collins S, Seldin M, Richard D, Warden C, Bouilland F, Ricquier D (1998) BMCP1, a novel mitochondrial carrier with high expression in the central nervous system of humans and rodents, and respiration uncoupling activity in recombinant yeast. J Biol Chem 273:34611-34615.

Schwab S, Spranger M, Aschoff A, Steiner T, Hacke W (1997) Brain temperature monitoring and modulation in patients with severe MCA infarction. Neurology 48:762-767.

Simoneau JA, Kelly DE, Neverova M, Warden CH (1998) Overexpression of muscle uncoupling protein-2 content in human obesity associates with reduced skeletal muscle lipid utilization. FASEB J 12:1739-1745.

Simonyan RA, Skulachev VP (1998) Thermoregulatory uncoupling in heart muscle mitochondria: involvement of the ATP/ADP antiporter and uncoupling protein. FEBS Lett 436:81-84.

Wu Z, Puigserver P, Andersson U, Zhang C, Adelmant G, Mootha V, Troy A, Cinti S, Lowell B, Scarpulla RC, Spiegelman BM (1999) Mechanisms controlling mitochondrial biogenesis and respiration through the thermogenic coactivator PGC-1. Cell 98:115-124. 